The final publication is available at Elsevier via https://doi.org/10.1016/j.brainres.2017.08.025 @ 2017. This manuscript version is made available under the CC-BY-NC-ND 4.0 license http://creativecommons.org/licenses/by-nc-nd/4.0/

\title{
The effect of type of afferent feedback timed with motor imagery on the induction of cortical plasticity
}

N Mrachacz-Kersting ${ }^{1}, \mathrm{M} \mathrm{Voigt}^{1}$, AJT Stevenson ${ }^{1}$, S Aliakbaryhosseinabadi $^{1}, \mathrm{~N} \mathrm{Jiang}{ }^{2}, \mathrm{~K} \mathrm{Dremstrup}^{1}$ and D Farina $^{3}$

${ }^{1}$ Center for Sensory-Motor Interaction (SMI), Department of Health Science and Technology, Aalborg University, Fredrik Bajers Vej 7 D-3, Aalborg - DK 9220, Denmark

${ }^{2}$ Department of Systems Design Engineering, University of Waterloo, Waterloo, Canada

${ }^{3}$ Department of Bioengineering, Imperial College London, London, UK

Grant: This study was funded by a grant from Det Obelske Familiefond.

Corresponding Author:

Natalie Mrachacz-Kersting

Address: Fredrik Bajers Vej 7 D3, 9220 Aalborg.

Email: nm@hst.aau.dk

Telephone: +459635 7571

FAX: +4598154008

Keywords: Brain-Computer-Interface, afferent feedback, cortical plasticity 


\section{Introduction}

Brain-computer-interfaces ( $\mathrm{BCls}$ ) designed for neuromodulation detect user intent from the brain activation patterns and send a command to an external device that reproduces the intended movement without the conventional routes via nerves and muscles (Wolpaw 2013; Wolpaw and Winter Wolpaw 2012). Since the original report by Daly et al (Daly et al. 2009), demonstrating the effectiveness of a non-invasive $\mathrm{BCl}$ intervention in stroke patients, there have been numerous studies conducted in this patient population (for a recent review see (Soekadar et al. 2015)). Here, the $\mathrm{BCl}$ may be implemented to either assist movements, thus replacing the lost function through assistive devices (Pfurtscheller et al. 2003; Ethier et al. 2012; Collinger et al. 2013), or conversely to induce neuroplasticity and thus restore normal motor function (Ang et al. 2009; Broetz et al. 2010; Cincotti et al. 2012; Daly et al. 2009; Kasashima-Shindo et al. 2015; Li et al. 2014; Mukaino et al. 2014; Mrachacz-Kersting et al. 2016; Pichiorri et al. 2015; Ramos-Murguialday et al. 2013; Young et al. 2014). In the latter case, $\mathrm{BCls}$ have to be designed to follow the principles of learning. That is, the control of the external device, irrespective of whether it is an electrical stimulator or a robotic actuator, has to be timed such that the elicited afferent feedback arrives at the primary motor cortex (M1) at the appropriate time.

To date the general consensus is that memory formation and learning follow the principle of associativity first developed by Hebb (Hebb 1949). When a postsynaptic cell fires just prior to receiving a weak presynaptic input, synapses are strengthened. Later animal studies confirmed this theory (Bliss and Lomo 1973; Bliss and Collingridge 1993) that is known as associative longterm potentiation (LTP). In both intact and lesioned participants, a peripheral afferent volley that arrives at the motor cortex when it is depolarized using non-invasive transcranial magnetic stimulation (TMS) induces plasticity. The induced plasticity rapidly evolves, it is long lasting and specific to the target muscle, and it is dependent on both NMDA receptor and calcium channel activation (Stefan et al. 2000; Stefan et al. 2002; Wolters et al. 2003; Stefan et al. 2006; CastelLacanal et al. 2007). It thus expresses many of the properties of LTP.

The TMS stimulus may be replaced by a more natural activation of M1 such as due to motor imagination. Motor imagination is associated to movement related cortical potentials (MRCP; (Mrachacz-Kersting et al. 2012) which are slowly developing potentials commencing 
approximately one to two seconds prior to movement execution, with peak negative phase during movement execution (for a review see (Shibasaki and Hallett 2006)). Since it may be detected prior to movement occurrence, it is an ideal signal modality that may be extracted from noninvasive electroencephalography (EEG) to control an external device.

In previous studies, we have demonstrated that this type of intervention induces neuroplasticity at the level of M1 in both healthy and chronic stroke patients (Mrachacz-Kersting et al. 2012; Xu et al. 2014; Mrachacz-Kersting et al. 2016). However, plastic changes were observed only if the artificially generated afferent signal was timed to reach $\mathrm{M} 1$ during the peak negative phase of the MRCP. Therefore, we developed methods for online detection of MRCPs that could trigger the induction of afferent feedback in an asynchronous manner (Niazi et al. 2012; Xu et al. 2014) and we termed the resulting intervention associative $\mathrm{BCl}$. Interestingly, in different studies using this concept, we observed that plasticity was induced irrespective of whether the afferent feedback was generated by a single electrical stimulus delivered at an intensity just above motor threshold (Mrachacz-Kersting et al. 2012), or a passive dorsiflexion movement induced by an actuated orthosis (Xu et al. 2014). However, for this $\mathrm{BCl}$ to be used within the daily clinical routine, it would be desirable to provide a feedback that is typically used by the existing therapies. These include functional electrical stimulation and passive ankle angle movements provided by a robotic device (for a review see (Laffont et al. 2014)).

In this study, we compared the effects of eliciting afferent feedback either by FES or by an active orthosis on the induced plasticity in an associative $\mathrm{BCl}$. However, to eliminate the confounding effect of variability in MRCP detection accuracy among subjects when comparing the feedback modalities, the timing of PN of the MRCP with respect to a cue was identified from a training set where participants were asked to perform or attempt to perform the motor task and subsequently used for the actual intervention. Therefore, in this study we do not directly test the online detection of $\mathrm{MRCP}$ with a $\mathrm{BCl}$ during the intervention but we rather focus on the comparison between feedback types. The aim was to quantify plastic changes in healthy participants exposed to an associative intervention when providing either FES or a passive dorsiflexion movement. For this purpose, cortical changes were assessed prior to, immediately following, and 30 minutes after the interventions while spinal changes were quantified with the stretch reflex. 


\section{Results}

\subsection{Reliability of the MRCP}

All participant performed 30 dorsiflexion movements prior to the two interventions. An average of $2 \pm 3$ trials and $2 \pm 4$ trials were rejected due to eye-blinks or movement artefacts in the $\mathrm{BCl}_{\mathrm{FES}}$ and $\mathrm{BCl}_{\text {passive }}$ sessions, respectively. Figure 1 shows the mean PN time (and SE) for each participant for the two $\mathrm{BCl}$ sessions while Figure 2 contains single trial MRCPs (and the average MRCP) for one participants for the $\mathrm{BCl}_{\mathrm{FES}}$ (Figure $\mathrm{2A}$ ) and $\mathrm{BCl}_{\text {passive }}$ (Figure $2 \mathrm{~B}$ ) intervention days. Across all participants, the PN occurred at $15 \pm 55 \mathrm{~ms}$ (mean and standard deviation) and $13 \pm 12 \mathrm{~ms}$ (for the $\mathrm{BCl}_{\mathrm{FES}}$ and $\mathrm{BCl}_{\text {passive }}$ sessions, respectively) in relation to the cue indicating to perform the movement. The time of the occurrence of the PN between the two sessions was not statistically different $\left(t_{11}=0.955, p=0.36\right)$.

\subsection{Changes in the output properties of the motor cortex for the $\mathrm{BCl}_{\mathrm{FES}}$ and $\mathrm{BCl}_{\text {passive }}$ intervention}

The amplitude of the TA MEPs evoked at the highest stimulation intensity prior to the interventions across all participants attained mean ( \pm SE) values of $529 \pm 133 \mu \mathrm{V}$ and $512 \pm 114 \mu \mathrm{V}$ for the $\mathrm{BCl}_{\mathrm{FES}}$ and $\mathrm{BCl}_{\text {passive }}$ interventions, respectively. The two-way rmANOVA on the preintervention measures found no significant interaction between intervention and stimulation intensity, $F_{(1.32,14.53)}=0.23, p=0.704$. After pooling the interaction term, the main effect of intervention was not significant, $F_{(1,11)}=0.52, p=0.486$, indicating that the experimental sessions started with a similar baseline excitability across all participants.

Figure $3 \mathrm{~A}$ and $\mathrm{B}$ shows the mean MEP data for one participant prior to, following and 30 minutes

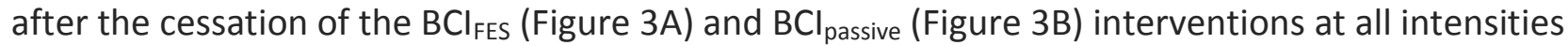
tested. For this participant, the maximum MEP evoked at the highest stimulation intensity increased from $714.7 \mu \mathrm{V}$ (pre) to $829.4 \mu \mathrm{V}$ (post) to $862.7 \mu \mathrm{V}$ (30 minutes post) for the $\mathrm{BCl}_{\mathrm{FES}}$ intervention and from $830.6 \mu \mathrm{V}$ (pre) to $879.9 \mu \mathrm{V}$ (post) and $1060 \mu \mathrm{V}$ (30 minutes post) for the $\mathrm{BCl}_{\text {passive }}$ intervention.

Figure $3 \mathrm{C}$ and $\mathrm{D}$ show the mean TA MEP amplitudes across all participants immediately following (Figure $3 \mathrm{C}$ ) and 30 minutes after (Figure3D) the $\mathrm{BCl}_{\mathrm{FES}}$ and $\mathrm{BCl}_{\text {passive }}$ interventions for all 
stimulation intensities. Data are expressed as a percentage of the corresponding pre-intervention TA MEP amplitudes for all stimulation intensities.

In the full model three-way rmANOVA, the three-way interaction and all two-way interactions were not significant (all $p^{\prime} s \geq 0.097$ ). After pooling the two- and three-way interaction terms, there was a significant main effect of time, $F_{(2,22)}=4.44, p=0.024$. Fisher's least significant difference (LSD) post-hoc analysis revealed that mean $( \pm S D)$ values TA MEP amplitudes were significantly larger immediately following $(280 \pm 46 \mu \mathrm{V})$ and 30 minutes after $(291 \pm 47 \mu \mathrm{V})$ the $\mathrm{BCl}$ interventions compared to pre-intervention MEPs $(243 \pm 50 \mu \mathrm{V})$ regardless of intervention type and stimulation intensity ( $p^{\prime} s=0.029$ and 0.039 , respectively). There was no significant difference between TA MEP amplitudes immediately following and 30 minutes after the $\mathrm{BCl}$ interventions ( $p$ $=0.490)$. Furthermore, there was a significant main effect of stimulation intensity, $F_{(1.08,11.92)}=$ $18.02, p=0.001$. Fisher's LSD post-hoc analysis revealed that mean $( \pm \mathrm{SD})$ values TA MEP amplitudes were significantly larger at stimulation intensities of 140\% RMT (536 $\pm 106 \mu \mathrm{V})$ compared to $130 \%(434 \pm 86 \mu \mathrm{V}), 120 \%(393 \pm 58 \mu \mathrm{V}), 110 \%(201 \pm 32 \mu \mathrm{V}), 100 \%(108 \pm 9 \mu \mathrm{V})$, and $90 \% \operatorname{RMT}(43 \pm 6 \mu \mathrm{V})$ regardless of intervention type and stimulation time (all $\left.p^{\prime} s \leq 0.002\right)$. In addition, TA MEP amplitudes were also significantly larger at stimulation intensities of: $130 \%$ RMT compared to $120 \%, 110 \%, 100 \%$, and $90 \%$ RMT (all $p$ 's $\leq 0.002$ ); $120 \%$ RMT compared to $110 \%$, $100 \%$, and $90 \%$ RMT (all $p$ 's $\leq 0.005$ ); $110 \%$ RMT compared to $100 \%$ and $90 \%$ RMT (both $p$ 's $\leq$ $0.011)$; and $100 \%$ compared to $90 \%$ RMT $(p<0.001)$. There was no significant main effect of intervention, $F_{(1,11)}=0.38, p=0.550$, indicating that the TA MEP changes occurred independently of the type of $\mathrm{BCl}$ intervention used.

\subsection{Control experiment: Changes in spinal excitability}

Eight participants were exposed to 30 unexpected plantarflexion movements prior to and following the two interventions. These had an amplitude of 4-6 deg and a velocity of 200-300 degs

${ }^{1}$. An example of one participant for changes in ankle angle (Figure $4 \mathrm{~A}$ and $\mathrm{B}$ upper trace) and the corresponding EMG recording from the TA (Figure 4A and B lower traces) are shown in Figure 4A and $\mathrm{B}$ for the $\mathrm{BCl}_{\text {passive }}$ and the $\mathrm{BCl}_{\mathrm{FES}}$ intervention respectively. For this participant the stretch reflex was comprised of three distinct peaks with an onset latency of $44 \mathrm{~ms}$ and a SLR peak latency of 74 ms. The SLR component of the stretch reflex did not change significantly for either the 
$\mathrm{BCl}$ passive or the $\mathrm{BCl}_{\mathrm{FEs}}$ intervention $\left(t_{7}=-0.267, \mathrm{p}=0.798\right.$ and $t_{7}=0.355, \mathrm{p}=0.733$ for the $\mathrm{BCl}_{\text {passive }}$ and the $\mathrm{BCl}_{\text {FEs }}$ intervention respectively). Figure $4 C$ shows the average size of the SLR prior to and following both interventions for all eight participants. The background level of activation during the imposed plantarflexion perturbations did not differ significantly pre and post for either of the two intervention ( $\mathrm{BCl}_{\text {passive: }} t_{7}=-1.348, \mathrm{p}=0.22$; pre: $150 \pm 43 \mu \mathrm{V}$, post: $156 \pm 43 \mu \mathrm{V} ; \mathrm{BCl}_{\mathrm{FEs}}: t_{7}=$ $0.075, \mathrm{p}=0.943$; pre: $203 \pm 39 \mu \mathrm{V}$, post: $202 \pm 38 \mu \mathrm{V}$ ). 


\section{Discussion}

We exposed healthy participants to an established associative intervention where the peripheral input consisted of either FES or a passive dorsiflexion movement timed such that the afferent inflow reached M1 during the peak negative phase of the MRCP. Both types of interventions resulted in a significant increase in the excitability of the corticospinal tract to the TA as assesses by TMS that outlasted the stimulation period by at least 30 minutes. No such changes were observed for the short latency component of the TA stretch reflex.

\subsection{Reliability of the MRCP}

Prior to the exposure to the interventions, the participants performed 30 dorsiflexion movements timed to a cue. This served to quantify the repeatability of the MRCP and, the timing of the peak negative phase in relation to the cue. Since participants will differ in their reaction to the visual cue (Mrachacz-Kersting et al. 2012), in the current protocol the afferent inflow was timed to arrive at the PN of the MRCP rather than at the onset of the visual cue shown to the participants. The results demonstrated that participants performed the movement in a similar manner across days since the PN did not vary significantly between the two sessions. This confirms previous reports where the MRCP was repeatable across sessions in both healthy participants (Mrachacz-Kersting et al. 2012) and chronic stroke patients (Mrachacz-Kersting et al. 2016).

\subsection{Changes in the output properties of the motor cortex for the $\mathrm{BCl}_{\mathrm{FES}}$ and $\mathrm{BCl}_{\text {passive }}$ interventions}

An associative $\mathrm{BCl}$ induces significant plasticity of $\mathrm{M} 1$ when applied to healthy participants in a single session (Mrachacz-Kersting et al. 2012; Xu et al. 2014). In our previous study we have demonstrated that neither electrical stimulation alone, passive dorsiflexion alone or imagery alone when repeated over such few trials have a significant effect on MEP sizes. Rather it is the combination of the afferent induced signal that is timed to arrive at the PN of the MRCP that is imperative for plasticity induction (Mrachacz-Kersting et al. 2012). The necessity of timing the peripheral stimulus so that the generated afferent volley arrives at precisely the PN phase of the MRCP is based on a theory proposed by (Hebb 1949). This implies that when an action potential arrives at a presynaptic neuron just prior to or concomitantly to the postsynaptic cell firing, the 
synapse is strengthened. In intact humans this may be tested by a protocol termed paired associative stimulation (PAS - (Stefan et al. 2000; Mrachacz-Kersting et al. 2007)). Here, a single stimulus is applied to the nerve that innervates the target muscle and once the generated afferent signal arrives at M1, a TMS stimulus is applied over that area of M1 that has projections to the target muscle. Since the initial reports, the peripheral stimulus as part of the PAS protocol has been modified to include either ipsilateral voluntary contraction of the target muscle (Kujirai et al. 2006), contralateral voluntary muscle activation (Kennedy and Carson 2008) or FES (MrachaczKersting 2013). As for PAS, results from the current study confirm that plasticity induction occurs irrespective of the type of afferent volley induced artificially. Since neither a passive movement alone (Mrachacz-Kersting et al. 2012) nor FES applied alone (Knash et al. 2003; Khaslavskaia et al. 2002) can induce significant changes in MEP size when applied over such a short time window (less than 10 minutes), the effects reported here are likely due to the continuous pairing of the afferent signal with the PN of the MRCP.

Afferent input arising from FES and passive movements presumably arrive at M1 via the somatosensory cortex, although it is known that $\mathrm{M} 1$ also receives afferent input from thalamocortical circuits (Kaneko et al. 1994a; Kaneko et al. 1994b). The afferent input between the $\mathrm{BCl}_{\mathrm{FES}}$ and $\mathrm{BCl}_{\text {passive }}$ interventions is likely to differ significantly since a passive movement will not only unload the target muscle but also stretch the antagonist and the activated muscle and cutaneous afferents will fire in an asynchronous manner. This is in contrast to FES where the intensity and frequency of the input would lead to recruitment of all afferents within the target nerve in a synchronous manner. However, somatosensory evoked potentials induced by a passive movement as performed here have an average onset latency of $47 \mathrm{~ms}$ (Petersen et al. 1998) which is similar to that following electrical stimulation (44 $\pm 2 \mathrm{~ms}$, (Mrachacz-Kersting et al. 2007). Thus,

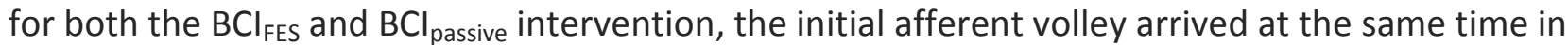
relation to the PN of the MRCP. If we assume that it is the arrival of the first afferent volley timed precisely with the PN of the MRCP that lead to the plasticity induction, it may not be surprising that both interventions showed a similar effect.

In our previous studies we applied a single peripheral nerve stimulus at MT (Mrachacz-Kersting et al. 2012; Mrachacz-Kersting et al. 2016) or a dorsiflexion movement (Xu et al. 2014) timed so that the generated afferent signal arrived at M1 during the PN phase of the MRCP. As for the $\mathrm{BCl}_{\mathrm{FES}}$ and 


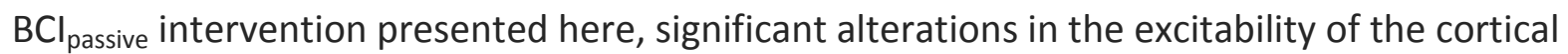
projections to the TA are evident after a single session that outlast the stimulation period. It appears that MEP changes may be induced regardless of the type of proprioceptive input supplied. From a clinical perspective this is desirable as some clinics may not have robotic actuators available but most use FES as part of the weekly rehabilitation of stroke patients. However, the type of proprioceptive input may have different effects on the motor cortical network (Rosenkranz and Rothwell 2006) when applied as part of an intervention. For example, PAS increases the MEP size of the target muscle, yet has no effect on short interval intracortical inhibition (SICI) or sensorimotor reorganization, while actual movement performance also increases MEP size, decreases $\mathrm{SICl}$, and significantly changes sensorimotor reorganization (Rosenkranz and Rothwell 2006). SICl and sensorimotor reorganization were not investigated in the current study, thus it remains speculative whether the FES or the passive movement targeted different components of the motor cortical network.

\subsection{Changes in spinal excitability for the $\mathrm{BCl}_{\mathrm{FES}}$ and $\mathrm{BCl}_{\text {passive }}$ intervention}

Alterations in MEP size can result due to changes in either cortical or spinal networks. However, since there were no changes in the spinally mediated component of the TA stretch reflex, it is unlikely that subcortical sites contributed to the effect. Recent reports suggest that at least some of the effects following PAS targeting upper limb muscles may occur at the spinal level (Meunier et al. 2007). However, not all participants that showed an increase in MEP size also had a concomitant increase in the $\mathrm{H}$-reflex. The $\mathrm{H}$-reflex only probes that pathway arising from muscle spindle la afferents while the TA stretch reflex has various components believed to arise from different muscle afferents (Kearney and Hunter 1984; Petersen et al. 1998) and may therefore be better suited to quantify spinal pathway changes. However, even with the stretch reflex it is not possible to probe the entire network of spinal pathways and thus it cannot be excluded that some of the changes may have occurred at subcortical or spinal sites.

\section{Conclusion}

Here we present an associative intervention with two types of peripherally applied proprioceptive inputs typically implemented in the clinical setting, FES and robot controlled passive movements. The two types of proprioceptive feedback induced similar changes in the excitability of the cortical 
projections to the TA, with no changes in the spinal stretch reflex. While these results provide strong support for the associative nature of the interventions, further studies are required to assess whether $\mathrm{BCl}_{\mathrm{FES}}$ and $\mathrm{BCl}_{\text {passive }}$ have similar effects on the motor cortical network.

\section{Methods and Materials}

\subsection{Participants}

Twelve participants (six females; aged $25.3 \pm 3.0$ years, mean \pm SD) provided written informed consent to take part in this study. At the time of the study, all participants were free of any known physical or neurological disorders. Approval for the study was provided by the scientific ethics committee for Nordjylland (Reference Number: N-20130039). The study was performed in accordance with the declaration of Helsinki.

During all experiments described below, participants were seated in a chair (Hip $90^{\circ}$, Knee $130^{\circ}$ ) with their right and left foot resting on separate footplates (see Figure $5 \mathrm{~A}-\mathrm{C}$ for the experimental set-up).

\subsection{Movement related cortical potential (MRCP)}

Ten channels of monopolar EEG were recorded using an active EEG electrode system (g. GAMMAcap ${ }^{2}$, Austria) and g.USBamp amplifier (gTec, GmbH, Austria) from FP1, Fz, FC1, FC2, C3, $\mathrm{Cz}, \mathrm{C} 4, \mathrm{CP} 1, \mathrm{CP} 2$, and Pz according to the standard international 10-20 system. The channel selection was based on the large Laplacian with $\mathrm{Cz}$ as the central channel (McFarland et al. 1997). The reference electrode was placed on $\mathrm{Fz}$ and the ground on the left earlobe. A single channel surface electromyography (EMG) was recorded from the tibialis anterior (TA) muscle to control for the participant's movement. All signals were sampled at a frequency of $256 \mathrm{~Hz}$ (16 bits accuracy) and hardware filtered from 0 to $100 \mathrm{~Hz}$.

Next, participants were asked to perform 30 dorsiflexions of their dominant foot in relation to a visual cue. A custom made Matlab script (R2014b, Mathworks ${ }^{\circledR}$ ) provided this cue via a screen positioned $2 \mathrm{~m}$ in front of the participant on when to mentally prepare, execute, and release the movement (Figure 5D). Participants were instructed to perform a single dorsiflexion movement as fast as possible when the cursor had reached the upwards turn and to maintain the new position for $2 \mathrm{~s}$, following which they relaxed again for $4-5 \mathrm{~s}$ prior to the next cue being provided. Data from 
recorded EEG trials was used to quantify the time of peak negativity of the MRCP's before proceeding to one of two interventions described under the section 'Interventions'.

\subsection{Feature extraction from the MRCP}

Matlab software (R2014b, Mathworks ${ }^{\circledR}$ ) was used to filter continuous EEG signals using a $2^{\text {nd }}$ order band-pass Butterworth filter from 0.05-10 Hz. EEG data were then divided into epochs of $4 \mathrm{~s}$ (from $2 \mathrm{~s}$ before to $2 \mathrm{~s}$ following the visual cue) for each movement and subsequently a Laplacian channel (McFarland et al. 1997) was used to enhance the MRCP in each epoch. Next, a window of $500 \mathrm{~ms}$ on either side of task onset was chosen. If any epoch's peak negativity was outside the selected window it was discarded. Epochs with EOG activity exceeding $140 \mu \mathrm{V}$ were also discarded. The remaining epochs were averaged and the mean peak negativity (PN) was defined as the time of occurrence of the minimum value of the averaged MRCP in relation to the visual cue. The mean PN was used to calculate the points in time for when to apply the peripheral stimulation in the subsequent intervention session.

\subsection{Recording and Stimulation}

The EMG activity was recorded by surface $\mathrm{Ag} / \mathrm{AgCl}$ electrodes (Ambu Neuroline $720, \mathrm{Ambu} \mathrm{A} / \mathrm{S}$, Denmark) placed over the belly of the right tibialis anterior (TA). The electrodes were placed in accordance with the recommendations of Cram et al. (Cram et al. 1998). Surface EMGs were preamplified and sampled at $2 \mathrm{kHz}$ using scientific software Mr. Kick II 2.3 (Knud Larsen, Center for Sensory-Motor Interaction, Aalborg University, Denmark) for recordings of the TA stretch reflex. The EMG amplifier pod supplied by Rogue Research Inc.as part of the Brainsight ${ }^{\mathrm{TM}}$ system (Rogue Research inc.), was used to collect MEP data. During the $\mathrm{BCl}$ intervention, EMG data were collected using the g.USBamps (g.tec $\mathrm{GmbH}$, Austria) at a sampling frequency of $256 \mathrm{~Hz}$.

A Magstim 200 (Magstim Company, Dyfed, UK) with a focal figure of eight double cone coil (110 $\mathrm{mm}$ diameter) was used to apply single transcranial magnetic stimulation (TMS) pulses to elicit a motor evoked potential (MEP) in the TA. The direction of the current was directed from posterior to anterior. 
Peripheral nerve stimulation was performed during one of the interventions. Stimulation of the common peroneal nerve (CPN) was applied using a NoxiTest isolated peripheral stimulator (IES 230). Stimulating electrodes ( $32 \mathrm{~mm}$, PALS ${ }^{\circledR}$ Platinum, Patented Conductive Neurostimulation Electrodes, Axelgaard Manufacturing Co., Ltd. USA) were placed on the skin overlying the deep branch of the right common peroneal nerve (CPN - L4 and L5) with the cathode proximal. A suitable position for stimulation, defined as the site where a maximal M-wave was produced in the TA with no activity from the synergistic peroneal muscles and no activity from the antagonist soleus (SOL), was identified. Palpation of SOL and peroneal muscles was performed during stimulation trials to ensure that this was occurring. The stimulation site corresponded to a point just anterior to the level of the caput fibulae. The pulse width was $1 \mathrm{~ms}$. Initially, the motor threshold (MT) was determined as that intensity where an M-wave became visible in the EMG signal. During the $\mathrm{BCl}_{\mathrm{FES}}$ intervention, the frequency was set to $20 \mathrm{~Hz}$, the intensity was adjusted to produce a dorsiflexion of the ankle joint corresponding to approximately 30 degrees and the duration of the stimulus train was one second. For the $\mathrm{BCl}_{\text {passive }}$ intervention, a custom-made robotic actuator performed a passive ankle movement with parameters set to induce the ankle trajectory during a normal gait cycle (Figure 7C).

\subsection{Experimental procedures}

Initially, the intensity for the magnetic stimulation was set at approximately $50 \%$ of the stimulator output (SO) to find the optimal site for evoking a MEP in the TA. The best spot for stimulation (also termed the hot-spot) was defined as the coordinate where the peak-to-peak amplitudes of the MEPs were greater in the target muscle than the amplitudes of adjacent coordinates for a given stimulus intensity. For all participants, this site was approximately $2-3 \mathrm{~cm}$ anterior to the vertex and a stimulation applied to this area also evoked a response in the SOL. Once the hot-spot was identified, it was marked using Brainsight ${ }^{\mathrm{TM}}$ (Rogue Research inc.) to ensure that the coil position was maintained so that the stimulation was always applied over the same area of M1.

Subsequently, the resting motor threshold (RMT), defined as the highest stimulus intensity that produced no more than five of ten consecutive TA MEPs with a peak to peak amplitude of $~ 50 \mu \mathrm{V}$ while the muscle was at rest, was identified. Next, 12 MEPs were elicited in the resting TA at each of six TMS intensities; $90,100,110,120,130$, and $140 \%$ of RMT (72 MEPs in total). The TMS stimuli 
were delivered every 5-7 s in a randomized order. The mean peak-to-peak TA MEP amplitudes were extracted pre, post, and 30 minutes following the cessation of the intervention.

\subsection{The interventions: $\mathrm{BCl}_{\mathrm{FES}}$ vs $\mathrm{BCl}_{\text {passive }}$}

All participants attended two intervention sessions spaced at least 48 hours apart. These consisted of either $\mathrm{FES}$ ( $\mathrm{BCl}_{\mathrm{FES}}$ intervention) or a passive dorsiflexion movement ( $\mathrm{BCl}_{\text {passive }}$ intervention) being imposed and timed so that the artificially generated afferent flow arrived at the PN of the MRCP as outlined in our previous publication (Mrachacz-Kersting et al. 2012). The timing was calculated according to the following equation: mean PN-50 ms. The 50 ms represents the mean latency for the afferent inflow resulting from the peripheral stimulus to reach the somatosensory cortex plus a cortical processing delay and is based on previous work (Mrachacz-Kersting et al. 2007). All participants were asked to imagine a dorsiflexion movement 30 times according to the cue in Figure 5D. An example from a single participant during the $\mathrm{BCl}_{\mathrm{FES}}$ intervention is shown in Figure 6 . Figure 6A shows an example of the MRCP generated during a voluntary dorsiflexion (obtained during the MRCP acquisition as described under section 5.2), the associated EMG activity of the TA is shown in Figure $6 \mathrm{~B}$, and the $\mathrm{EMG}$ during the $\mathrm{BCl}_{\mathrm{FES}}$ activated dorsiflexion movement (i.e. during the intervention) in Figure 6C. The vertical line indicates the PN of the MRCP. An example of the same participant during the $\mathrm{BCl}_{\text {passive }}$ intervention is shown in Figure 7. Figure 7A shows an example of the MRCP generated during a voluntary dorsiflexion (obtained during the MRCP acquisition as described under section 5.2), Figure 7B the $E M G$ activity during the $\mathrm{BCl}_{\text {passive }}$ intervention, and Figure $7 \mathrm{C}$ the ankle angle during the $\mathrm{BCl}_{\text {passive }}$ intervention. The vertical line indicates the PN of the MRCP.

It has to be noted that the experimental procedure in this study did not include the online detection of MRCP. Therefore, the interventions were not $\mathrm{BCl}$ sessions but rather cue-based imagination or execution and triggering of peripheral stimuli. However, the trigger was timed based on a preliminary assessment of the MRCP timing with respect to the cue. This choice was preferred over the online detection of MRCPs since the focus of the study was to study the effect of the type of afferent feedback elicited and variability in detection accuracy of MRCPs among subjects and among conditions would have not made it possible to compare the interventions. Despite the interventions are not based on $\mathrm{BCl}$ decoding, we have still denoted them as $\mathrm{BCl}_{\mathrm{FES}}$ and 
$\mathrm{BCl}_{\text {passive }}$ since their comparison according to the experimental procedure proposed in this study has a direct implication for the design of an associative $\mathrm{BCl}$ based on the same principles but with online detection.

\subsection{Control experiment: Stretch reflex recording}

It is not possible to differentiate if alterations in the MEP are due to changes in spinal or cortical circuitry based on the MEP alone. For this purpose, TA stretch reflexes were elicited prior to and following the $\mathrm{BCl}_{\mathrm{FES}}$ and $\mathrm{BCl}_{\text {passive }}$ interventions in eight participants (five males, three females; age: $26.3 \pm 3.1$ years). The right leg was affixed to an electrically controlled custom made actuator such that the anatomical ankle axis of rotation was aligned with the fulcrum of the actuator. The foot segment of the right leg of the participant was firmly strapped to a custom-made plate that extended from the actuator, thus producing a tight interface between the arm of the motor and the foot of the participant, ensuring that the movement of the actuator was transmitted solely to the ankle joint. The angular position of the actuator was monitored by an angular displacement transducer (Transtek DC ADT series 600). The participants were asked to produce three maximum voluntary contractions (MVC) of the TA, separated by three minutes of rest. The greatest of the three MVC forces was used as the reference MVC. The root mean square value of the rectified TA EMG for the MVC over a 1s period was calculated. Subsequently, the participants were provided with visual feedback via a computer screen displaying horizontal markings set at 5\% MVC and a vertical bar displaying the participant's current level of TA activation. Participants were asked to maintain the bar between the horizontal markings while the perturbations were applied without interfering with the imposed plantarflexion perturbations.

Thirty stretches were randomly applied at intervals ranging from 5 to $7 \mathrm{~s}$ (velocity: $200^{\circ} \mathrm{s}^{-1}$ to $300^{\circ} \mathrm{s}^{-1}$; amplitude: $4^{\circ}$ to $6^{\circ}$; hold-time: $200 \mathrm{~ms}$ ). The angular velocity and the amplitude of the imposed perturbations were adjusted for each participant prior to the intervention so that the amplitude of the three response peaks observed in the TA EMG trace were approximately the same and also similar to the amplitude of the TA MEP prior to the intervention. The latency of the first response peak (termed M1 or alternatively SLR in the literature) was extracted from the data both prior to and immediately following the intervention. The root mean square (RMS) value of a 
window extending $10 \mathrm{~ms}$ on either side of the SLR was calculated and used as an indication of the size of this component of the TA stretch reflex.

\subsection{Statistical analysis}

A Student's paired $t$-test was used to establish the reliability of the PN of the MRCP and changes in the size of the SLR component of the TA stretch reflex for both intervention days. A two-way repeated analysis of variance ( $r m A N O V A)$ was conducted on the pre-intervention measures with the factors intervention $\left(\mathrm{BCl}_{\mathrm{FES}}\right.$ and $\left.\mathrm{BCl}_{\text {passive }}\right)$ and TMS stimulation intensity $(90,100,110,120,130$ and $140 \%$ RMT). The effectiveness of the two interventions in inducing alterations of the corticospinal tract excitability was tested using a three-way rmANOVA with the factors time (pre, post and 30 minutes post intervention), intervention ( $\mathrm{BCl}_{\mathrm{FES}}$ and $\mathrm{BCl}_{\text {passive }}$ ) and $\mathrm{TMS}$ stimulation intensity $(90,100,110,120,130$ and 140\% RMT). Greenhouse-Geisser corrections were used in the case of sphericity being violated. The significance level was set to $p<0.05$.

Acknowledgements: The authors thank Mr. Jan Stavnshøj, and Mr. Knud Larsen for their technical Assistance, AC Lundgaard for assistance in data collection and all participants. 
References

Ang KK, Guan C, Chua KS, Ang BT, Kuah C, Wang C, Phua KS, Chin ZY, Zhang H (2009) A clinical study of motor imagery-based brain-computer interface for upper limb robotic rehabilitation. Conf Proc IEEE Eng Med Biol Soc 2009:5981-5984. DOI 10.1109/IEMBS.2009.5335381 [doi]

Bliss TVP, Collingridge GL (1993) A synaptic model of memory: long-term potentiation in the hippocampus. Nature 361:31-39

Bliss TVP, Lomo T (1973) Long-lasting potentiation of synaptic transmission in the dentate area of the anaesthetized rabbit following stimulation of the perforant path. J Physiol (Lond ) 232:331-356

Broetz D, Braun C, Weber C, Soekadar SR, Caria A, Birbaumer N (2010) Combination of braincomputer interface training and goal-directed physical therapy in chronic stroke: a case report. Neurorehabil Neural Repair 24:674-679. DOI 10.1177/1545968310368683 [doi]

Castel-Lacanal E, Gerdelat-Mas A, Marque P, Loubinoux I, Simonetta-Moreau M (2007) Induction of cortical plastic changes in wrist muscles by paired associative stimulation in healthy subjects and post-stroke patients. Exp Brain Res 180:113-122

Cincotti F, Pichiorri F, Arico P, Aloise F, Leotta F, de Vico Fallani F, Millan Jdel R, Molinari M, Mattia D (2012) EEG-based Brain-Computer Interface to support post-stroke motor rehabilitation of the upper limb. Conf Proc IEEE Eng Med Biol Soc 2012:4112-4115. DOI 10.1109/EMBC.2012.6346871 [doi]

Collinger JL, Wodlinger B, Downey JE, Wang W, Tyler-Kabara EC, Weber DJ, McMorland AJ, Velliste $M$, Boninger ML, Schwartz AB (2013) High-performance neuroprosthetic control by an individual with tetraplegia. Lancet 381:557-564. DOI 10.1016/S0140-6736(12)61816-9 [doi]

Cram J, Kasman G, Holtz J (1998) Introduction to Surface Electromyography. Aspen Publication, Gaithersburg

Daly JJ, Cheng R, Rogers J, Litinas K, Hrovat K, Dohring M (2009) Feasibility of a new application of noninvasive Brain Computer Interface $(\mathrm{BCl})$ : a case study of training for recovery of volitional motor control after stroke. J.Neurol.Phys.Ther. 33:203-211

Ethier C, Oby ER, Bauman MJ, Miller LE (2012) Restoration of grasp following paralysis through brain-controlled stimulation of muscles. Nature 485:368-371. DOI 10.1038/nature10987 [doi]

Hebb DO (1949) The Organization of Behavior: A Neuropsychological Theory, vol. 1. Lawrence Erlbaum Associates Inc, Mahwah, NJ

Kaneko T, Caria MA, Asanuma H (1994a) Information processing within the motor cortex. I. Responses of morphologically identified motor cortical cells to stimulation of the somatosensory cortex. J Comp Neurol 345:161-171. DOI 10.1002/cne.903450202 [doi] 
Kaneko T, Caria MA, Asanuma H (1994b) Information processing within the motor cortex. II. Intracortical connections between neurons receiving somatosensory cortical input and motor output neurons of the cortex. J Comp Neurol 345:172-184. DOI 10.1002/cne.903450203 [doi]

Kasashima-Shindo Y, Fujiwara T, Ushiba J, Matsushika Y, Kamatani D, Oto M, Ono T, Nishimoto A, Shindo K, Kawakami M, Tsuji T, Liu M (2015) Brain-computer interface training combined with transcranial direct current stimulation in patients with chronic severe hemiparesis: Proof of concept study. J Rehabil Med 47:318-324. DOI 10.2340/16501977-1925 [doi]

Kearney RE, Hunter IW (1984) System identification of human stretch reflex dynamics: tibialis anterior. Exp Brain Res 56:40-49

Kennedy NC, Carson RG (2008) The effect of simultaneous contractions of ipsilateral muscles on changes in corticospinal excitability induced by paired associative stimulation (PAS). Neurosci Lett 445:7-11

Khaslavskaia S, Ladouceur M, Sinkjaer T (2002) Increase in tibialis anterior motor cortex excitability following repetitive electrical stimulation of the common peroneal nerve. Exp Brain Res 145:309315

Knash M, Kido A, Gorassini M, Chan KM, Stein R (2003) Electrical stimulation of the human common peroneal nerve elicits lasting facilitation of cortical motor-evoked potentials.

Experimental Brain Research 153:366-377

Kujirai K, Kujirai T, Sinkjaer T, Rothwell JC (2006) Associative plasticity in human motor cortex during voluntary muscle contraction. J Neurophysiol 96:1337-1346

Laffont I, Bakhti K, Coroian F, van Dokkum L, Mottet D, Schweighofer N, Froger J (2014) Innovative technologies applied to sensorimotor rehabilitation after stroke. Ann Phys Rehabil Med 57:543551. DOI 10.1016/j.rehab.2014.08.007 [doi]

Li M, Liu Y, Wu Y, Liu S, Jia J, Zhang L (2014) Neurophysiological substrates of stroke patients with motor imagery-based Brain-Computer Interface training. Int J Neurosci 124:403-415. DOI 10.3109/00207454.2013.850082 [doi]

McFarland DJ, McCane LM, David SV, Wolpaw JR (1997) Spatial filter selection for EEG-based communication. Electroencephalography and Clinical Neurophysiology 103:386-394

Meunier S, Russmann H, Simonetta-Moreau M, Hallett M (2007) Changes in spinal excitability after PAS (paired associative stimulation). J Neurophysiol 97:3131-3135

Mrachacz-Kersting N (2013) Paired-associative stimulation. In: Farina D, Jensen W, Akay M (eds) Introduction to Neural Engineering for Motor Rehabilitation (IEEE Press Series in Biomedical Engineering). Wiley-IEEE press, pp 529-547 
Mrachacz-Kersting N, Fong M, Murphy BA, Sinkjaer T (2007) Changes in excitability of the cortical projections to the human tibialis anterior after paired associative stimulation. J Neurophysiol 97:1951-1958. DOI 01176.2006 [pii]

Mrachacz-Kersting N, Jiang N, Stevenson AJ, Niazi IK, Kostic V, Pavlovic A, Radovanovic S, DjuricJovicic M, Agosta F, Dremstrup K, Farina D (2016) Efficient neuroplasticity induction in chronic stroke patients by an associative brain-computer interface. J Neurophysiol 115:1410-1421. DOI 10.1152/jn.00918.2015 [doi]

Mrachacz-Kersting N, Kristensen SR, Niazi IK, Farina D (2012) Precise temporal association between cortical potentials evoked by motor imagination and afference induces cortical plasticity. J Physiol 590:1669-1682. DOI 10.1113/jphysiol.2011.222851 [doi]

Mukaino M, Ono T, Shindo K, Fujiwara T, Ota T, Kimura A, Liu M, Ushiba J (2014) Efficacy of braincomputer interface-driven neuromuscular electrical stimulation for chronic paresis after stroke. J Rehabil Med 46:378-382. DOI 10.2340/16501977-1785 [doi]

Niazi IK, Mrachacz-Kersting N, Jiang N, Dremstrup K, Farina D (2012) Peripheral electrical stimulation triggered by self-paced detection of motor intention enhances motor evoked potentials. IEEE Trans.Neural Syst.Rehabil Eng 20:595-604

Petersen N, Christensen LO, Morita H, Sinkjaer T, Nielsen J (1998) Evidence that a transcortical pathway contributes to stretch reflexes in the tibialis anterior muscle in man. J Physiol (Lond ) 512 (Pt 1):267-276

Pfurtscheller G, Muller GR, Pfurtscheller J, Gerner HJ, Rupp R (2003) 'Thought'--control of functional electrical stimulation to restore hand grasp in a patient with tetraplegia. Neurosci Lett 351:33-36. DOI S0304394003009479 [pii]

Pichiorri F, Morone G, Petti M, Toppi J, Pisotta I, Molinari M, Paolucci S, Inghilleri M, Astolfi L, Cincotti F, Mattia D (2015) Brain-computer interface boosts motor imagery practice during stroke recovery. Ann Neurol 77:851-865. DOI 10.1002/ana.24390 [doi]

Ramos-Murguialday A, Broetz D, Rea M, Laer L, Yilmaz O, Brasil FL, Liberati G, Curado MR, GarciaCossio E, Vyziotis A, Cho W, Agostini M, Soares E, Soekadar S, Caria A, Cohen LG, Birbaumer N (2013) Brain-machine interface in chronic stroke rehabilitation: a controlled study. Ann Neurol 74:100-108

Rosenkranz K, Rothwell JC (2006) Differences between the effects of three plasticity inducing protocols on the organization of the human motor cortex. Eur J Neurosci 23:822-829

Shibasaki H, Hallett M (2006) What is the Bereitschaftspotential? Clin Neurophysiol 117:2341-2356

Soekadar SR, Birbaumer N, Slutzky MW, Cohen LG (2015) Brain-machine interfaces in neurorehabilitation of stroke. Neurobiol Dis 83:172-179. DOI 10.1016/j.nbd.2014.11.025 [doi] 
Stefan K, Kunesch E, Benecke R, Cohen LG, Classen J (2002) Mechanisms of enhancement of human motor cortex excitability induced by interventional paired associative stimulation. J Physiol (Lond) 543:699-708

Stefan K, Kunesch E, Cohen LG, Benecke R, Classen J (2000) Induction of plasticity in the human motor cortex by paired associative stimulation. Brain 123:572-584

Stefan K, Wycislo M, Gentner R, Schramm A, Naumann M, Reiners K, Classen J (2006) Temporary Occlusion of Associative Motor Cortical Plasticity by Prior Dynamic Motor Training. Cereb Cortex $16: 376-385$

Wolpaw JR (2013) Brain-computer interfaces. Handb.Clin.Neurol. 110:67-74

Wolpaw JR, Winter Wolpaw E (2012) Brain-Computer Interfaces - Principles and Practice, vol. 1st Edition. Oxford University Press, New Yorl

Wolters A, Sandbrink F, Schlottmann A, Kunesch E, Stefan K, Cohen LG, Benecke R, Classen J (2003) A Temporally Asymmetric Hebbian Rule Governing Plasticity in the Human Motor Cortex. J Neurophysiol 89:2339-2345

Xu R, Jiang N, Mrachacz-Kersting N, Lin C, Asin Prieto G, Moreno JC, Pons JL, Dremstrup K, Farina D (2014) A closed-loop brain-computer interface triggering an active ankle-foot orthosis for inducing cortical neural plasticity. IEEE Trans Biomed Eng 61:2092-2101. DOI 10.1109/TBME.2014.2313867 [doi]

Young BM, Nigogosyan Z, Remsik A, Walton LM, Song J, Nair VA, Grogan SW, Tyler ME, Edwards DF, Caldera K, Sattin JA, Williams JC, Prabhakaran V (2014) Changes in functional connectivity correlate with behavioral gains in stroke patients after therapy using a brain-computer interface device. Front Neuroeng 7:25. DOI 10.3389/fneng.2014.00025 [doi] 
Figure Legend

Figure 1: The mean PN time (and SE) for each participant for the two training part of the $\mathrm{BCl}_{\mathrm{FES}}$ and

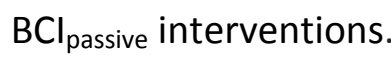

Figure 2: Single trial MRCPs and the average MRCP for one participant for the $\mathrm{BCl}_{\mathrm{FES}}(\mathrm{A})$ and $\mathrm{BCl}_{\text {passive }}(\mathbf{B})$ interventions days respectively.

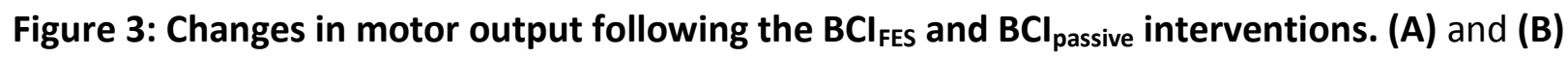
The average of 12 TA MEP traces for $90-140 \%$ RMT prior to, following, and 30 minutes after the $\mathrm{BCl}_{\mathrm{FES}}$ and $\mathrm{BCl}_{\text {passive }}$ interventions for one participant. (C) and (D) Mean TA MEP amplitudes for 110140\% RMT across all participants immediately following and 30 minutes after both interventions. Data are expressed as a percentage of pre-intervention values (black dashed line). Black bars represent the $\mathrm{BCl}_{\mathrm{FES}}$ intervention and the white bars represent the $\mathrm{BCl}_{\text {passive }}$ intervention. Error bars represent SEM.

Figure 4: Stretch reflex data. (A) and (B) Right ankle angle $\left({ }^{\circ}\right)$ for the $\mathrm{BCl}_{\mathrm{FES}}$ and $\mathrm{BCl}_{\text {passive }}$ interventions, respectively. The vertical dashed line indicates the onset of the imposed plantarflexion perturbation. (C) and (D) TA rectified EMG trace prior to (thin line) and following (thick line) the $\mathrm{BCl}_{\mathrm{FES}}$ and $\mathrm{BCl}_{\text {passive }}$ interventions. Each trace is the mean of 30 trials. Data are for $\mathrm{n}$ $=1$. (E) The mean SLR amplitude across all participants prior to and following the $\mathrm{BCl}_{\mathrm{FES}}$ and

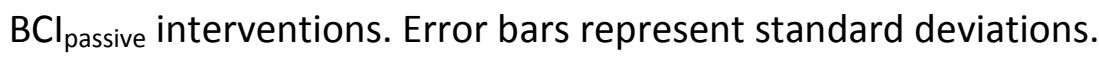

Figure 5: Schematic of the experimental set-up. (A) Pre-intervention quantification of the excitability of the cortical projections to the target muscle tibialis anterior (TA) using non-invasive transcranial magnetic stimulation (TMS). Participants were seated with the TA relaxed while 72 stimuli at six different intensities were applied. (B) Schematic of the $\mathrm{BCl}_{\mathrm{FES}}$ and $\mathrm{BCl}_{\text {passive }}$ interventions. Participants watched a screen placed $2 \mathrm{~m}$ in front of them on which a cue provided information on when to imagine the dorsiflexion movement. Relevant brain activity was measured, detected and converted into an output command for an electrical stimulator or a robotic actuator. The induced sensory signal produced was timed to arrive at the motor cortex during the time of maximum activation of the motor cortex as seen in the electroencephalographic (EEG) signal. Thirty such pairs were performed. (C) Immediately postintervention and 30 minutes later, measures as for A. (D) The visual display shown to the 
participants during the intervention. FOCUS appeared on the screen initially followed by the schematic of a step-function. Participants were required to start the imagined movement once the moving cursor (triangle) reached the upward slope. The word REST appeared last on the screen. Figure 6: The MRCP and associated TA EMG activity recorded during the dorsiflexion movement and for the $\mathrm{BCl}_{\mathrm{FES}}$ intervention. (A) The mean MRCP trace for one participant following 30 dorsiflexion movement. (B) The associated TA EMG activity and (C) the TA EMG trace during the application of FES during the $\mathrm{BCl}_{\mathrm{FES}}$ intervention. The vertical dashed line indicates the time of PN of the MRCP.

Figure 7: The MRCP and associated TA EMG activity recorded during the dorsiflexion movement

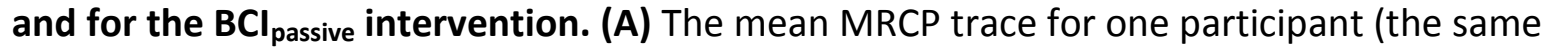
participant as for Figure 2) following 30 dorsiflexion movement. (B) The associated TA EMG activity and (C) the TA EMG trace during the application of the passive movement during the

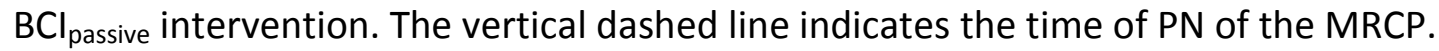


Figure 1
Click here to download Figure: Figure_1.docx Click here to download Figure: Figure 1.docx

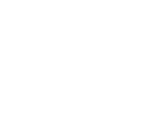

$\sqrt{2}$ (1)

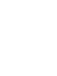
(1) (1) (1) (1) (1)

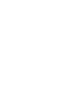
(1) (1)

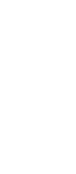
(1) (1) (1)

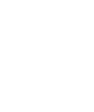

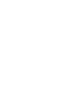
(1)

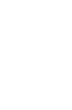

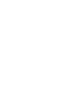

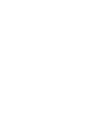
.

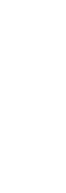
. . . . 列 . . .

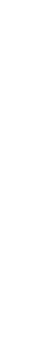

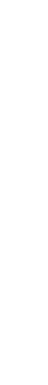

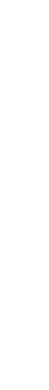

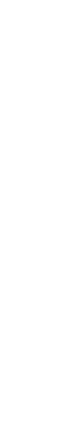
. . 列

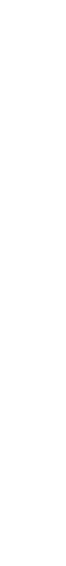

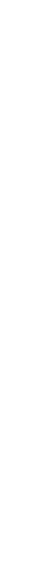

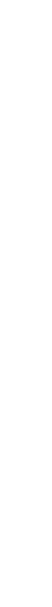
(1) (1) (1) 
Figure 2

Click here to download Figure: Figure_2.docx

Figure 2
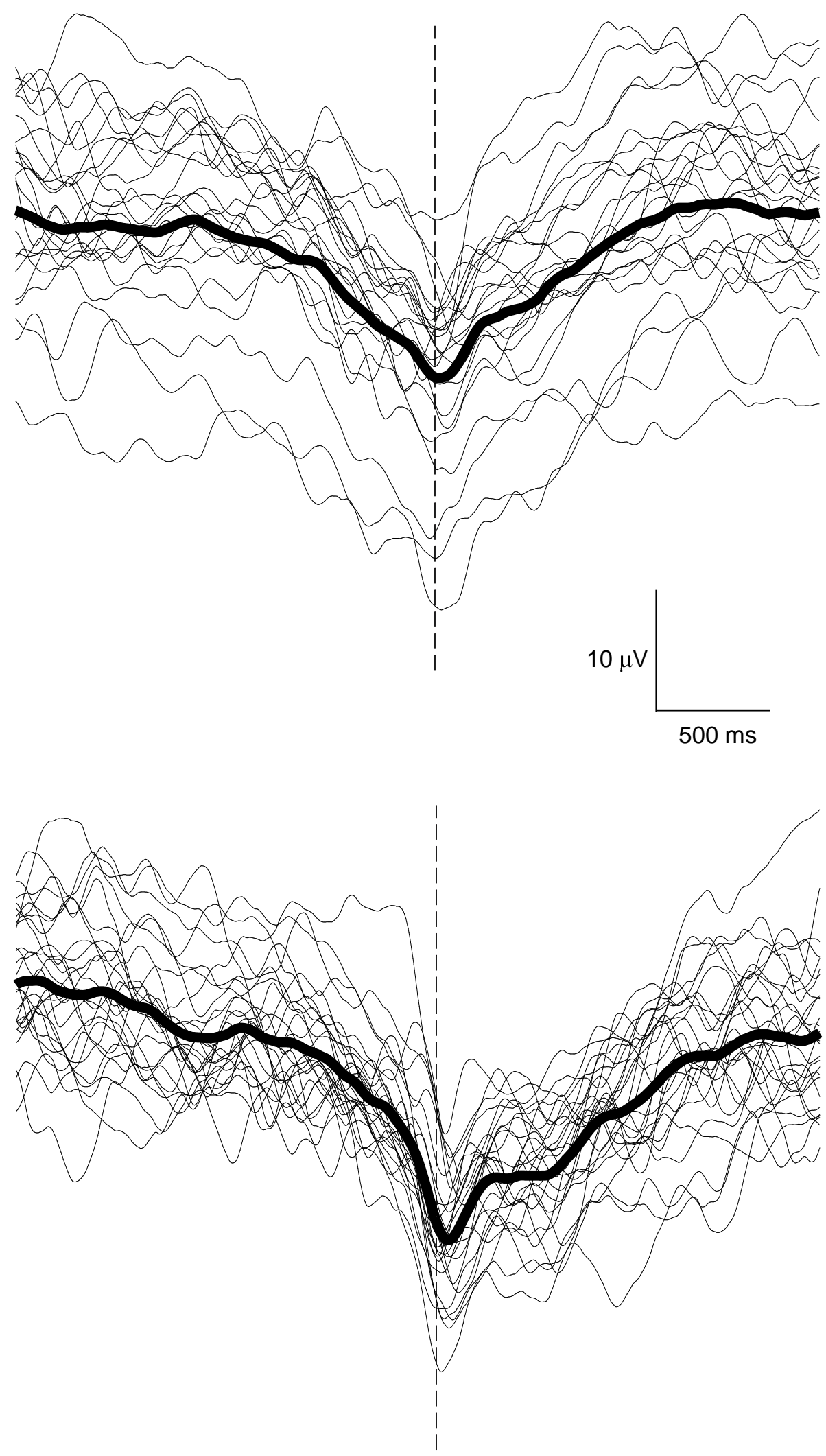
Click here to download Figure: Figure_3.docx

Figure 3

$\boldsymbol{A}$

Functional Electrical Stimulation

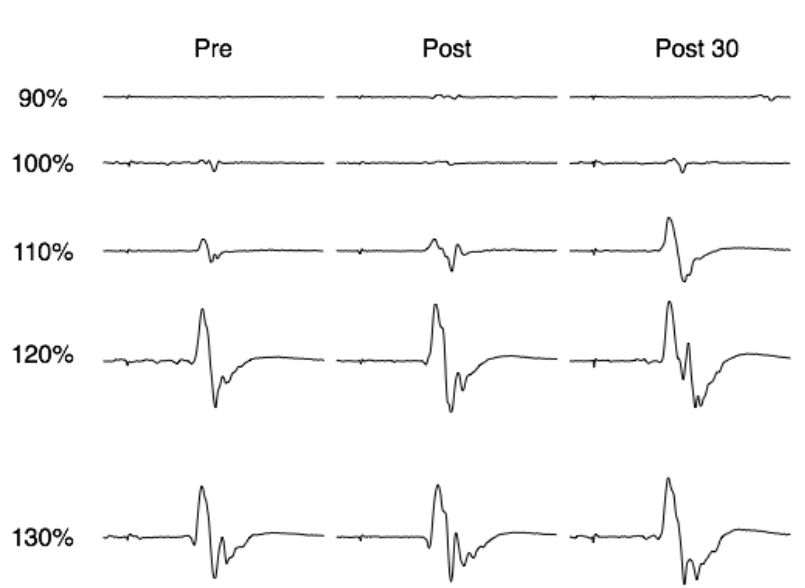

B
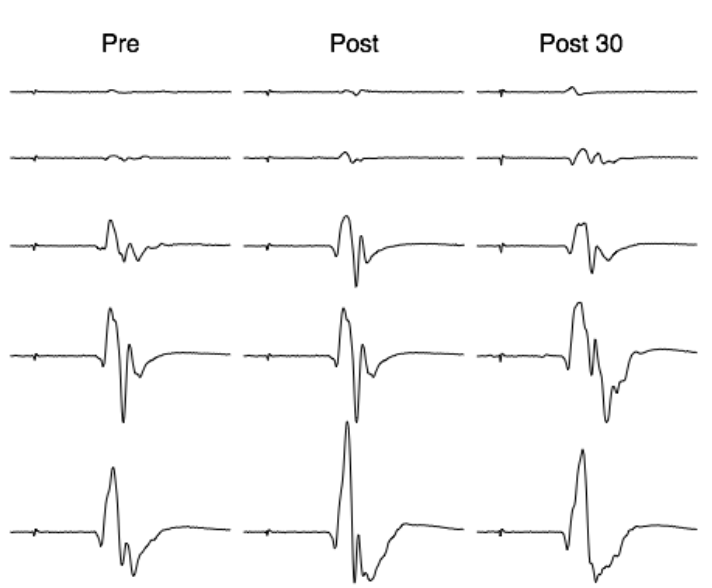

$140 \%+\sqrt{ }$

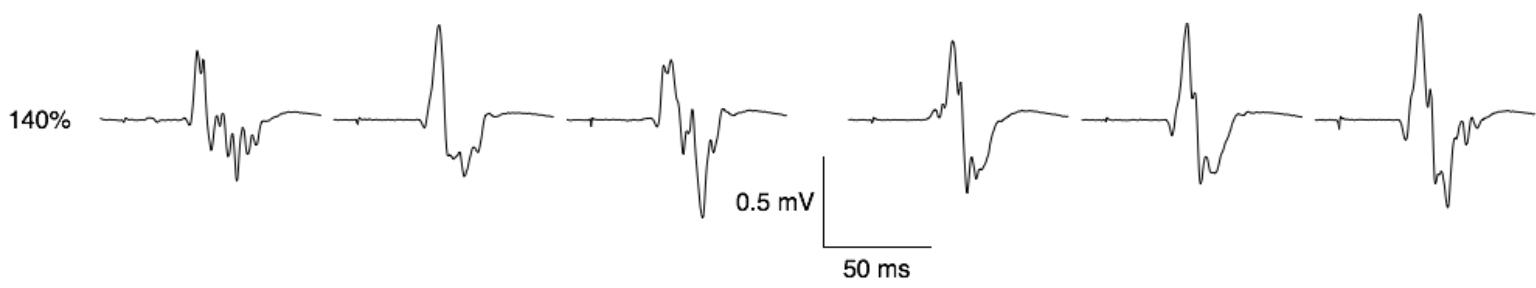

C

Post-Intervention

D

30 Minutes Post-Intervention

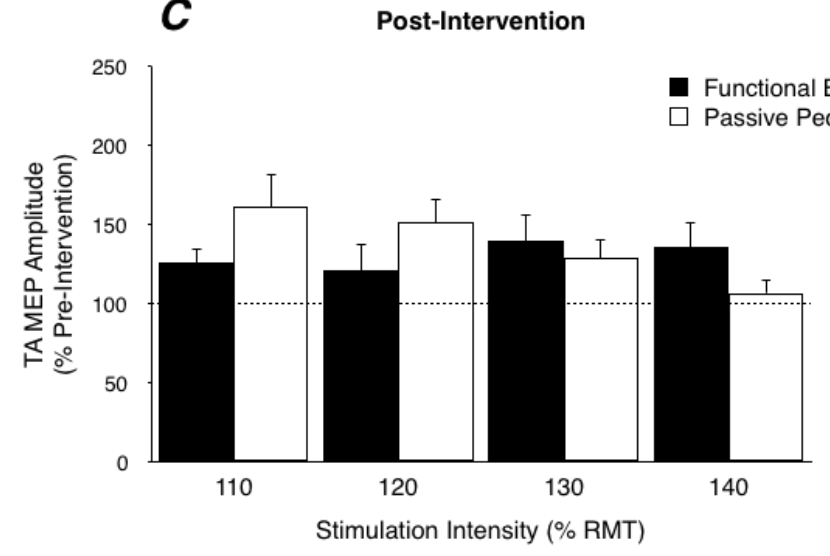

al Stimulation

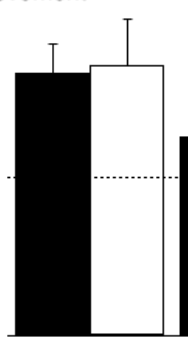

110

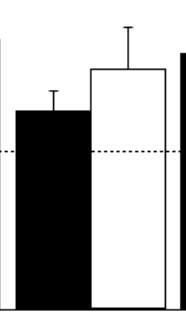

120

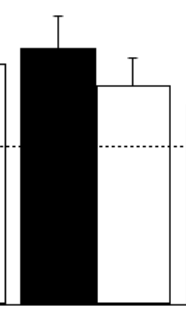

130

Stimulation Intensity (\% RMT)

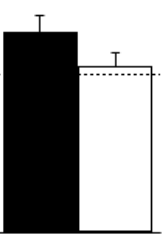

140 
Figure 4
Click here to download Figure: Figure_4.docx 
Figure 5
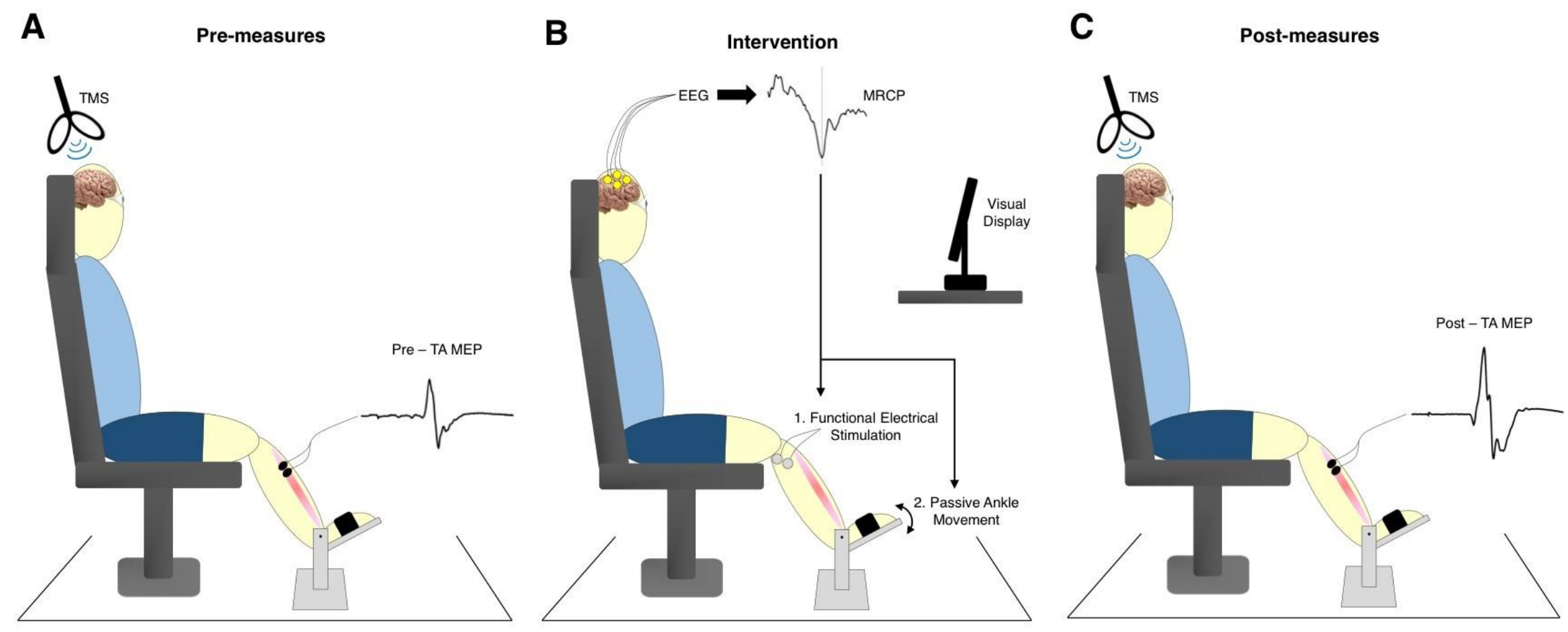

D Visual display during intervention

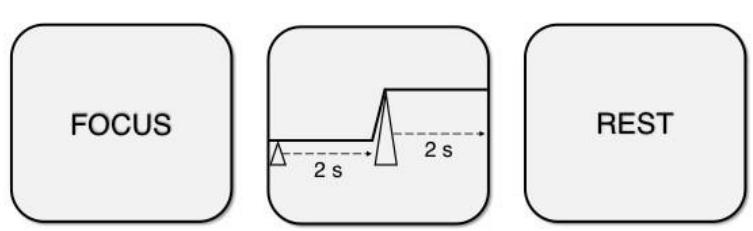


Figure 6

A

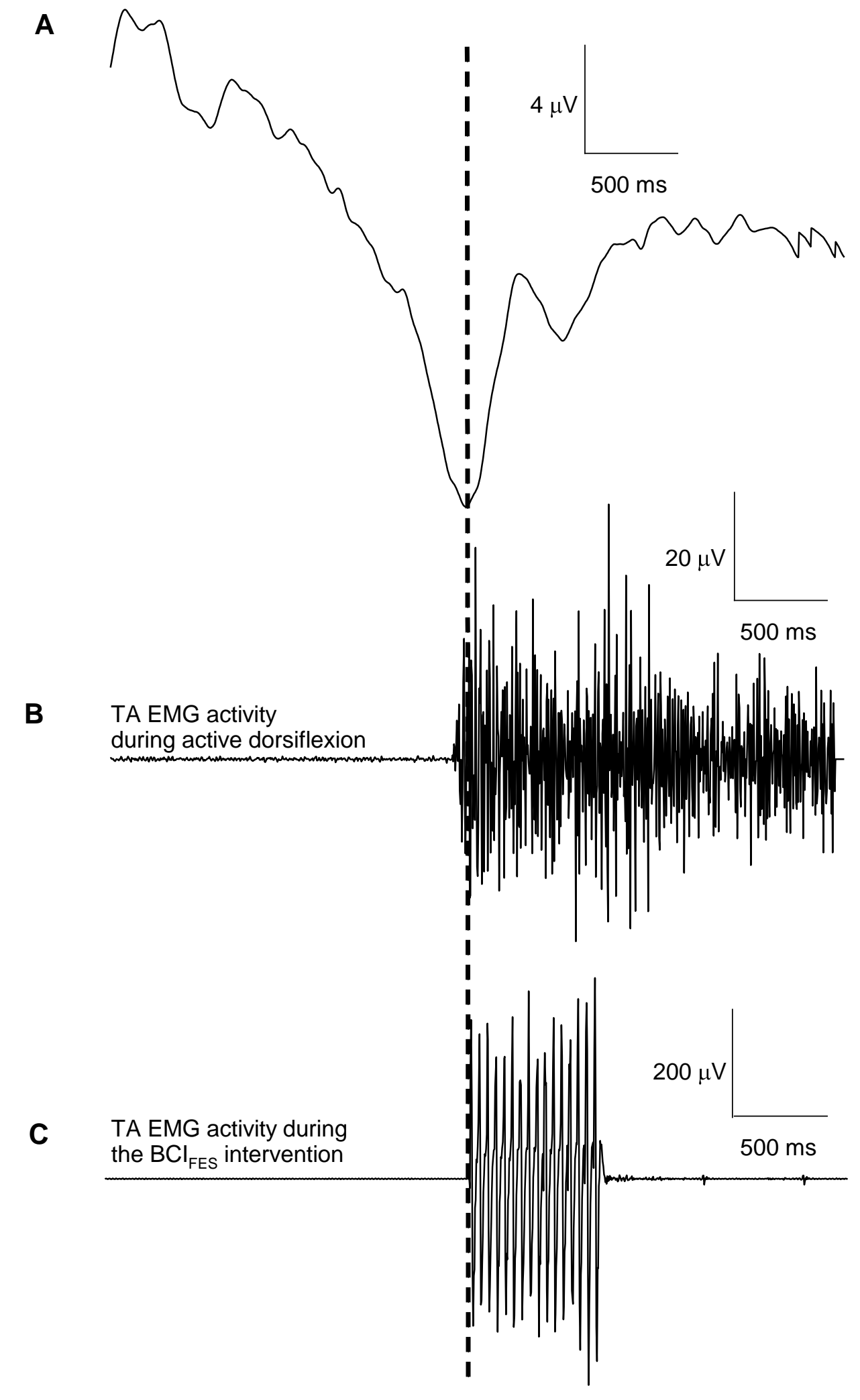


Figure 7

Click here to download Figure: Figure_7.docx

Figure 7

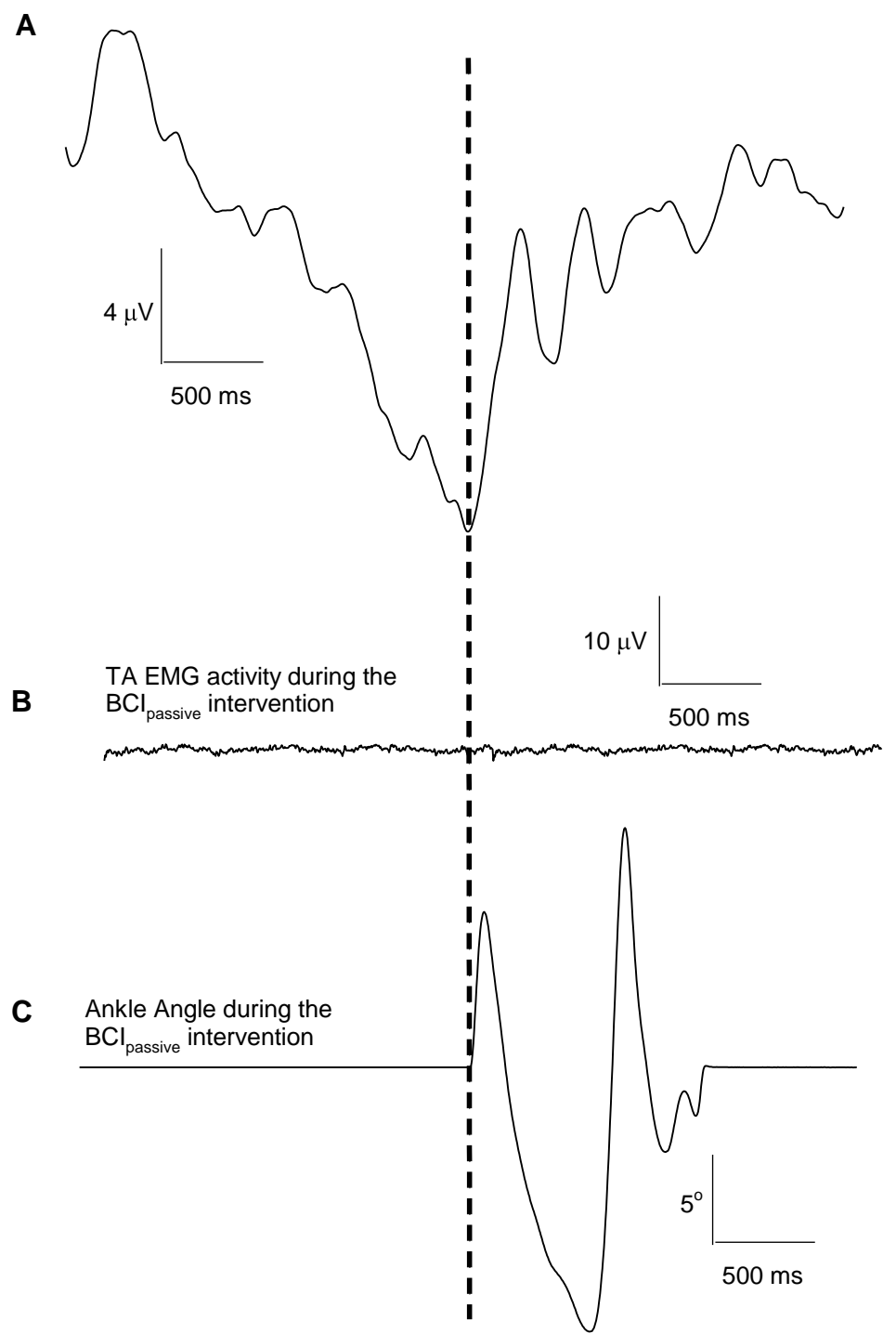

